\title{
PREVALENCE OF GIARDIA SPECIES IN CATTLE FAECAL MATTER IN SELECTED FARMS IN WEIJA AND KPONG MAJOR WATER SUPPLY HEADS TO ACCRA, GHANA
}

\author{
G. T. Mensah*, A. K. Annang, P. F. Ayeh-Kumi, J. A. Oppong And S. Niampoma \\ (G.T.M. \& S.N.: CSIR-Water Research Institute, P.O. Box AH38 Achimota; A.K.A.: \\ Noguchi Memorial Institute for Medical Research, College of Health Sciences Uni- \\ versity of Ghana, Legon; P.F.A-K.: Department of Microbiology, University of Ghana \\ Medical School, College of Health Sciences, University of Ghana, Korle-Bu; J.O.: De- \\ partment of Animal Biology and Conservation Science, University of Ghana, Legon). \\ *Corresponding author's email: mensgato@yahoo.com
}

\begin{abstract}
In developing countries including Ghana, giardiasis plays a major role in gastroenteritis in vertebrate. It poses health and socio-economic burden, and continues to be one of the causes of infant and calf mortality. Their infection continues to thrive in humans due to the zoonotic transmission of infected domesticated animals including cattle, dogs and cats, and their continual presence in water bodies. The objective of this study was to establish their presence and evaluate the prevalence of Giardia $s p$. in cattle faecal matter in the environment in the Kpong and Weija communities. The Iron-haematoxylin staining techniques was used to analyze the faecal samples in order to identify Giardia sp. (Student t- test and Chi square were the statistical analyses) used for the studies. About five percent (5.3\%) prevalence was obtained in both communities and this was significant $(\mathrm{p}>0.05)$. The parasite was found to be most prevalent $(9.4 \%)$ in calves less than 3 months old and this decreased with age of calf. It was also observed that Giardia plays an important role in the cause of diarrhoea in cattle. There is the need to educate people on the disease and its implication on the quality of water from the treatment plants.
\end{abstract}

Keywords: Giardia sp, water, contamination, diarrhoea, infant mortality.

\section{Introduction}

Giardia is a genus of parasitic protozoan that infects the small and large intestines of a broad range of vertebrate hosts, (Adam, 2001; Caccio \& Ryan, 2008). Considered among the common human intestinal protozoa, in the tropics (Thompson, 2000; Feng \& Xiao, 2011), G. duodenalis ranges in clinical severity from asymptomatic to pathogenic (Thompson, 2004). Both host factors (e.g. nutrition, immunity, co-infection with other agents) and pathogen factors (e.g. strain, infectious dose) are thought to contribute to the clinical severity of giardiasis, (Thompson, 2000). Giardia duodenalis is also notable for cross-species transmission (Thompson, 2013). According to Cook (1996), Giardia is one of the most important zoonotic protozoan parasites that affect a wide range of domestic animals and man worldwide (Caccio \& Ryan, 2008). These organisms have emerged over the past decades as major water borne pathogens and are responsible for a 
number of outbreaks of gastrointestinal diseases in humans and animals around the world each year (Cacciò et al., 2005; Delport et al., 2014). Giardiasis is also recognized as a disease of travelers worldwide, with the highest prevalence in the developing world (Craun et al., 2005).

The prevalence of Giardia is definitely high in calves under six months of age as compared to adults and may be responsible for diarrhoea (Scott et al., 1995). Cryptosporidium sp. and Giardia sp. have been reported to be second only to rotavirus as the causes of diarrhoea in newborn calves in Britain with prevalence of $80 \%$ and $62 \%$ respectively (Scott et al., 1995). This in part is due to the poor immunity in the newborn calves. There is increasing evidence to suggest that immunological factors are important in protecting mammalian hosts from re-infection. This suggests that multiple exposures to the parasites are required for the development of protective immunity (Farthing et al., 1996).

According to Farthing et al. (1996), Cryptosporidium and Giardia infections are seasonal and vary with rainfall in the temperate and tropical regions with the highest peak in periods of high rainfall. In a research conducted in Los Angeles the peak of transmission was found to be during the spring months (March-May). In Norway, prevalence is found to be higher in winter than in spring and summer (Batchelor et al., 2008). Though some studies on this disease had been done in Gha- na, its focused on the human disease with no report on the parasites in the environment in Ghana (Anim-Baidoo, 2013).

This present study was carried out to establish the presence of the parasite in the two communities which supply portable water to the Greater Accra Region of Ghana. In addition to parasite presence the study sought to establish the prevalence of the parasites in the two communities in order to inform policy in the development of control strategies for the prevention of human infections.

\section{Study area}

\section{Experimental}

The study was conducted in two communities namely, Joma near Weija in the Greater Accra Region, and Kpong in the Eastern Region. The Kpong and Weija water reservoirs supply drinking water to Accra and serve as host water bodies where other water bodies from surrounding communities drain into. Surface run-off water carries contaminants from surrounding communities' upstream serving as potential sources of faecal contamination to the Kpong Dam and the communities downstream.

Joma was selected for the study due to its position upstream of the Weija Dam from where water is treated for supply to Accra. Surface run-off carries contaminants from surrounding communities' downstream serving as potential sources of faecal contamination to the Weija Dam. 


\section{Kpong}

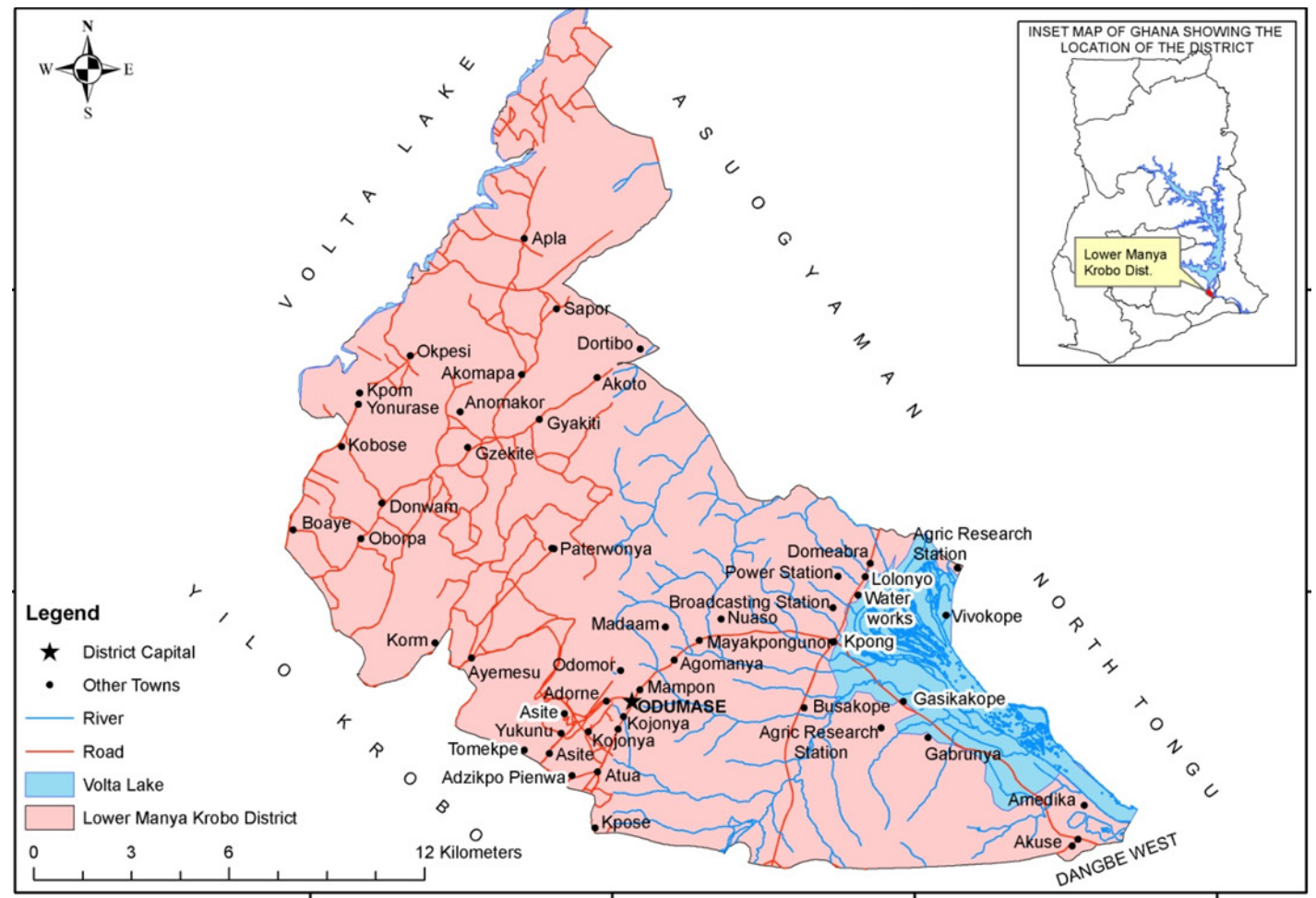

Fig. 1: Map of Lower Manya Krobo District showing the study communities.

Kpong is a town in the Manya Krobo District of the Eastern Region of Ghana. The co-ordinates of Kpong are $6^{\circ} 9^{\prime} 0^{\prime \prime}$ North, $0^{\circ} 0$ ' 0" East. The Kpong Township is noted for the Kpong dam constructed in 1981. The construction of the Akosombo dam in 1964 and the Kpong dam in 1981 on the Volta River created the Volta Lake in Ghana (Obeng-Asamoah et al., 1980). The impoundment of the river at Kpong caused an alteration of the existing ecological and bio- physical processes in the river basin such as slowing of the flow of the river, both upstream and downstream and flooding of cultivated fields, upstream. Over the years, this has led to an increase in the prevalence of protozoan and other parasitic diseases in areas around the Volta Lake (Biney, 1987). In addition to this, there is increased disease transmissions associated with inadequate sanitary systems in the lakeside settlements (Gordon \& Amatekpor, 1999). 


\section{Weija (Joma)}

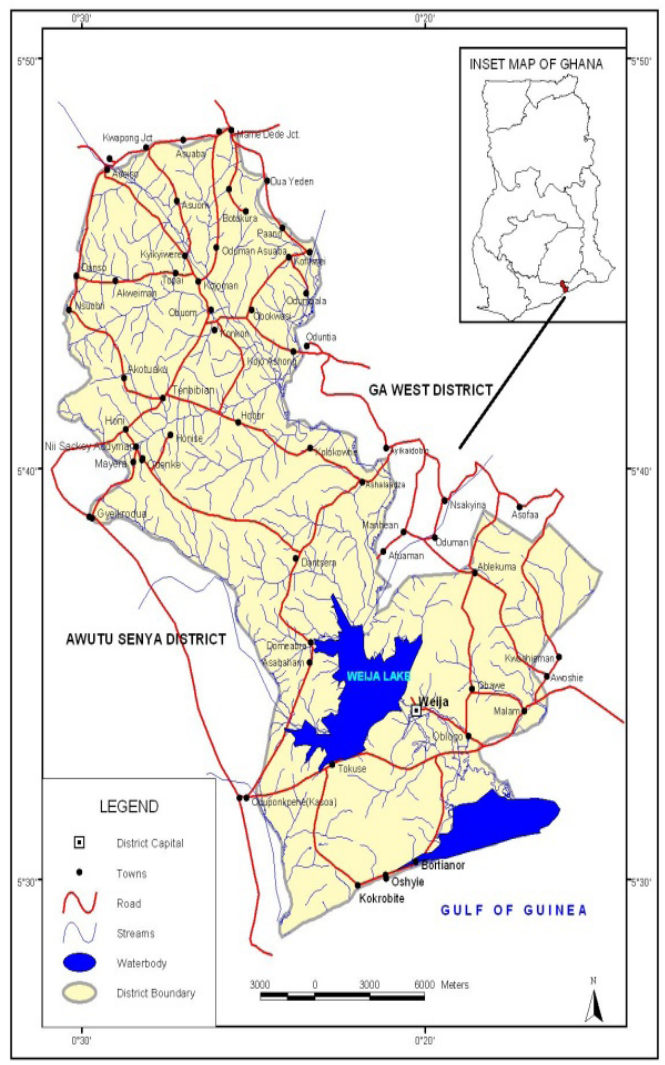

Fig. 2: Map of Ga South Municipality showing the study communities.

Weija is a suburb of Accra and its geographical coordinates are $5^{\circ} 34^{\prime} 0^{\prime \prime}$ North, $0^{\circ} 20^{\prime} 0^{\prime \prime}$ West. The Weija Lake, located $17 \mathrm{~km}$ west of Accra, capital of Ghana, has a shoreline of 48 $\mathrm{km}$. According to Ampofo (1996), the creation of the Weija Lake in 1979 by the Government of Ghana to supply portable water and to support irrigation and fisheries programmes has provided ideal conditions for disease transmission. The Weija Reservoir has a surface area of about 300 ha and a depth of about $7 \mathrm{~m}$. The reservoir lies at $5^{0} 35^{1} \mathrm{~N}$ and $0^{0} 22^{1} \mathrm{~W}$. It has a mean annual inflow of $54.2 \mathrm{~m}^{3} \mathrm{~S}^{-1}$. Its catchment lies in the Coastal Savanna Zone where rainfall is seasonal with two peaks in June and September. The main economic activities in the catchment of both reservoirs are fishing and crop farming.

There are many cattle kraals (farms) dotted in the upstream communities and the cattle are released on free range each day to feed in selected communities. The presence of the parasites in the communities have public health implications on the inhabitants that is the cause diarrhoea in children under five years of age. This can impact the socio economic activities as it will reduce income generating hours for mothers (with children infected with diarrhoea) as most of these women are peasant farmers and petty traders. Most of the women are the bread winners of their families as they are single mothers.

Since cattle had been found to be one of the natural reservoirs of the Giardia $s p$. (Barutzki \& Schaper,2003; Vermeulen et al., 2015), a study to establish the role of the cattle in the transmission of the parasite was conducted.

\section{Study population of cattle}

Animals used in this study included cattle (mixed breed of White Fulani, Ndama and Sokoto gudali) from four selected privately owned farms. Two of the farms were located in Weija (Joma) named as farms A and B and two from Kpong named as farms $\mathrm{C}$ and $\mathrm{D}$. Each farm had a cattle population of $80-120$ giving an average of 100 cattle per farm. In the adult population, there was an average of 10 bulls, $10-15$ young adults, 50 cows and eight calves per farm. The animals were categorized as calves ( $<3$ months old), weaners (3-8 months old) and adults ( $>8$ months old). The animals live in open houses with muddy 
floors and they were taken out each morning for grazing and brought back in the evening to rest in their kraals. All the animals graze on similar pasture therefore having the same feed composition. The presence or absence of diarrhoea in the animals was also recorded.

\section{Collection of samples:}

\section{Faecal samples}

The study focused on the contamination of the environment by faecal matter of the cattle containing these parasites, which is expected to find its way into water bodies through run off water after rainfall. In all, 320 faecal samples of cattle were collected. Of these, 160 were sampled from Weija (Joma) comprising of 80 each from farm A and farm B, and 160 from the Kpong community comprising of 80 each from farm C and farm D. Samples were taken from all age groups. Fresh faecal matter of each animal (cattle) were taken just after it had been dropped in the morning and stored in a small sterile plastic disposable container. Faecal sampling was done twice in each farm. The containers were labelled according to kraal and sites. Faecal samples were then transported to the Noguchi Memorial Institute for Medical Research, University of Ghana and preserved in $2.5 \%$ potassium dichromate at $40^{\circ} \mathrm{C}$ for laboratory analysis. Other information recorded included health status (diarrhoeic or non-diarrhoeic) and age of each cattle. The overall sampling period was between November 2008 and May 2009 covering both dry and wet seasons.

\section{Sample analysis}

The Iron-Haematoxylin staining technique was used to prepare the faecal samples for microscopic examination to identify Giardia sp. A thin smear of normal saline-emulsified faeces was prepared on glass slides and observed under a light microscope to identify moving flagellates. Those found to be positive were taken through series of preparations to permanently stain them on the slides for further identification. The positive smears were further placed in a working Schaudinn's solution before the smear could dry. The slide was left overnight to stand in the Schaudinn's solution. The slide was transferred into a $70 \%$ iodine-alcohol solution for about five minutes to remove the mercuric chloride crystals. The specimens were rehydrated by passing successively through $95 \%$ and $70 \%$ alcohol and run over water for five (5) minutes each. They were transferred again into $70 \%$ alcohol for about five minutes. These were then transferred into a Koplin jar and tap water was allowed to flow gently over the slides for about 10 minutes. The slides were then placed in a working solution of the Iron-Haematoxylin staining solution for $4-5$ minutes. The slides were transferred into a Koplin jar and tap water was allowed to flow over it for 10 minutes. The slides were again transferred into $70 \%$ alcohol for five minutes. The slide was further transferred into $95 \%$ alcohol for 5 minutes. It was placed in absolute (100\%) alcohol for five minutes and then transferred into xylene (xylol) for 10 minutes to clear. The wet film was covered with Clarite, Permount or Canada Balsam, and then mounted with a clean dry cover slip.

\section{Statistical analyses}

Samples were classified as negative (no cysts/ oocysts found), or positive, the latter being graded as $1+$ when $<10$ cysts/oocysts on average were present in each of 20 fields of view, as $2+$ with 10 to 20 cysts/oocysts on average in each of 20 fields of view, or as $3+$ with $>20$ cysts/oocysts on average in each of 20 fields 
at x400 magnification, respectively. Statistical tests included t-test for comparisons of means, and confidence interval calculations. Differences were considered statistically significant if $p<0.05$. The prevalence was evaluated with respect to age, intensity of infection, geographical distribution (Kpong or Weija) and multiple parasitic infections (Rumsey, 2010).

\section{Results and Discussion}

\section{Prevalence of Giardia}

This study showed that 17 (5.3\%) of the 320 examined cattle were infected with Giardia sp. The cattle faecal matter from Kpong showed a relatively higher prevalence (5.6\%) of Giardia $s p$ than that from Weija (5\%). In Kpong a higher prevalence $(7.5 \%)$ was recorded in cattle faecal matter from Farm D compared to a lower prevalence $(3.5 \%)$ in cattle faecal matter from Farm A (Fig. 3). Difference in prevalence between the various farms was not significant.

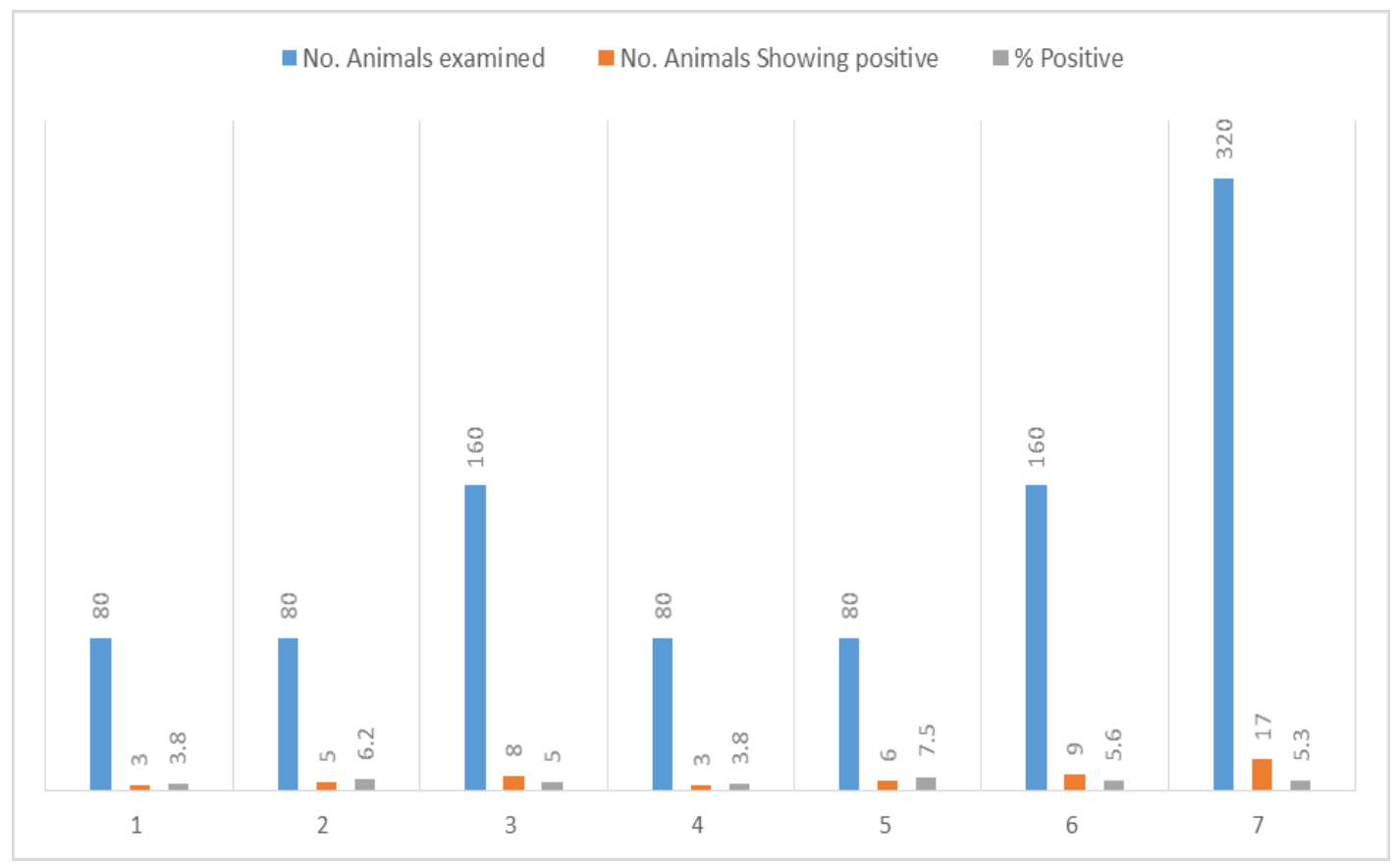

Fig. 3: The prevalence of Giardia cysts in the screened farms.

Comparing the prevalence among the age groups showed that the weaned calves were the least infected (2.8\%) whereas the calves showed the highest prevalence of infection (9.4\%) (Fig.3). The difference between the prevalence in calves and weaned calves was significant $(p=0.01)$. 


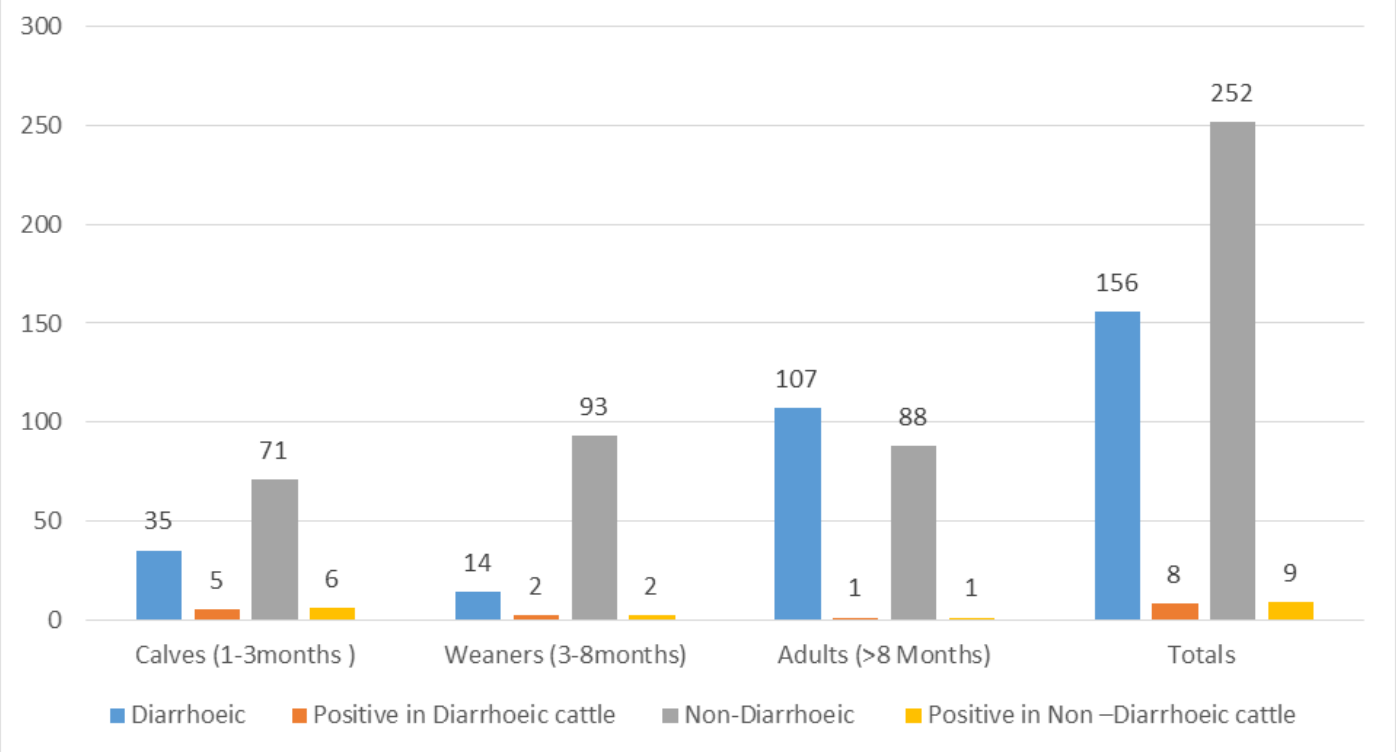

Fig. 4: Occurrence of Giardia cysts in different age groups of cattle.

A total of 68 of the 320 cattle had diarrhoea of which 8 were detected positive for Giardia cysts. Of these, the calves were the most affected and the weaned calves were the least affected. Again, 9 out of the remaining 252, though having non-diarrhoea stool were diagnosed positive for Giardia infection. The calves were the most affected but no significant differences $(p>0.05)$ were observed as prevalence recorded were very low (Fig. 4).

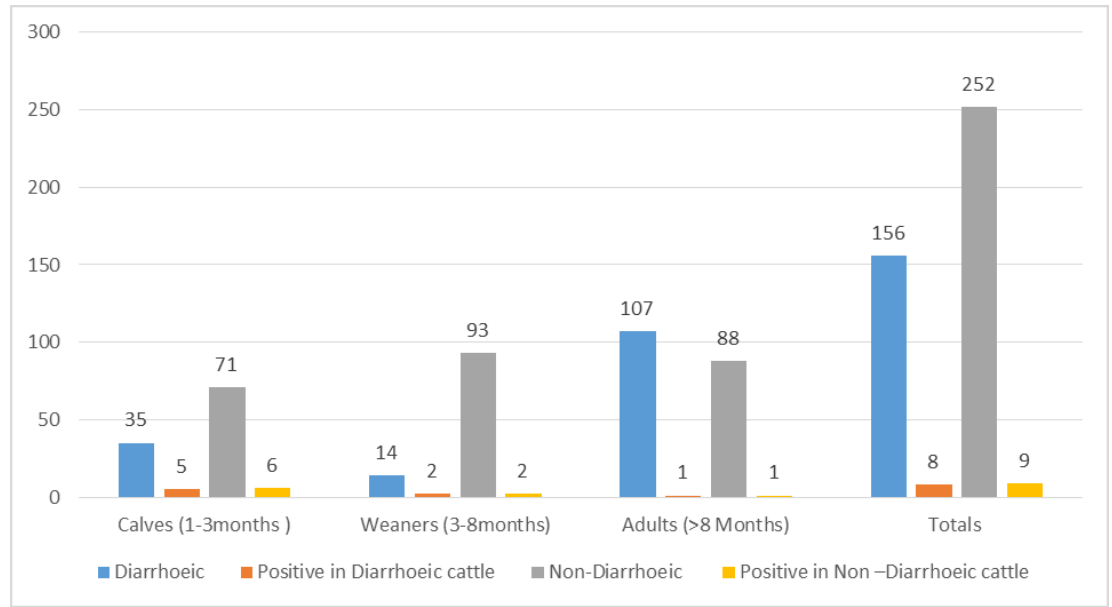

Fig. 5: The association between the age of the cattle, presence of diarrhoea and occurrence of Giardia cysts. 
Giardia duodenalis is considered to be one of the most frequently encountered intestinal parasites, with a worldwide prevalence of $7 \%$ $-40 \%$ in cattle (Heymans et al., 1987). It was observed in this study that the average prevalence of Giardia infection in both communities was $5.3 \%$ which is lower than that reported in other studies conducted in other countries (Mahato et al.,2018). Of the screened farms, Farm D (Kpong) had the highest prevalence of infection Giardia sp. This could be due to poor management practices on the farm and high humidity which led to availability of moisture in the study area which vital for survival of the cysts, since animals were living in open ranches with muddy floors. The presence of a dirty and muddy environment could lead to the persistence of Giardia cysts on the farm and more animals are likely to be exposed to the parasites.

Little is known about the extent to which acquired immunity after an infection with a particular Giardia duodenalis genotype will protect against infection with another species or genotype. It is not possible to determine whether the cattle diagnosed with either of these parasites had a persistent infection with the same species or genotype (Giardia duodenalis assemblages $\mathrm{A}, \mathrm{B}, \mathrm{C}, \mathrm{D}$ ) or whether they had been re-infected with another species/genotype.

Most of earlier studies have shown that calves are more likely to be infected with protozoan parasites (Hoskins et al., 1982; Reynolds et al., 1986; Kirkpatrick, 1988; Vanparijs et al., 1991; Overgauuw, 1997; Itoh et al., 2001; Jacobs et al., 2001; Barutzki \& Schaper, 2003). These findings share same observations in this study, where the young cattle were much more likely to be infected. A prevalence of $9.4 \%$ was recorded in calves less than
3 months old for Giardia sp. compared with $3.7 \%$ in adults. The prevalence among age groups was observed to decline with age. This predisposition may reflect immunological immaturity, with host resistance increasing with age (Kirkpatrick, 1988). The stress associated with weaning and movements during grazing may also lead to a compromise of the immune system of the calves and make them more susceptible to infection, thus contributing to the high prevalence in the young cattle.

Diarrhoea is the most common clinical symptom of cryptosporidiosis and giardiasis (Cook, 1996). In this study, out of the 68 diarrhoea stools collected, 8 (11.7\%) were diagnosed positive for Giardia, whereas out of the 252 non-diarrhoea stool collected 9 (3.6\%) were found to be positive for Giardia (Fig.5). This supports the assertion by Adam (2001) that Giardia sp. may play an important role as a cause of diarrhoea, which is an important factor in calf mortality. In addition, the duration of peak shedding for Giardia cysts in calves is longer (about 5 weeks) (Hamnes et al., 2007).

In Ghana, Klaus et al. (2007) showed that transmission occurs all year round indicating no seasonality in transmission. This is possibly due to its endemicity in this part of the world, such that the occurrence of these diseases continues throughout the year. According to Cook (1996) the transmission of Giardia is associated with unsanitary conditions. The tendency towards a higher prevalence of the parasites in the wet season could be due to the damp conditions and the suitable environment created for the parasites to thrive well during the rainy season (Adegbola et al., 1994). Enriquez et al. (1997) found that the burden of intestinal parasitic infection increases with rainfall. Other studies from Central America, South Africa, Kuwait and India also reported 
a high peak incidence during the rainy season (Leach et al., 2000; Iqbal et al., 2001). It may be possible for seasonal rains to amplify low levels of source water contamination through water runoff that contains faeces of infected humans and animals into water bodies. This results in the higher numbers of cryptosporidiosis and giardiasis cases during high rainfall months as observed in this study.

However, there was no significant difference in the prevalence of Giardia infection in both towns $(p=0.62)$ even though there was a higher record of infection in Kpong than Weija. This may be due to the fact that there was a very low record of Giardia infections which makes it difficult to test for significance. In addition, the Kpong farms recorded a relatively higher prevalence of Giardia sp. as compared to the Weija dam in this study. This could be due to the absence of adequate sanitary facilities in the Kpong community and observed indiscriminate defecation by the inhabitants as well as free range defecation by domestic animals.

\section{Conclusion}

Giardia infections are common in cattle in the study area, with an average prevalence of $5.3 \%$ in both communities. Prevalence of the parasite was found to be higher in calves less than 3 months old and declined with age, Table 3 above.

The zoonotic potential of cattle in the transmission of Giardia infections in the communities cannot be ruled out.

\section{Acknowledgements}

The Authors are grateful to Dr. Y. Opoku-Ankomah former Director of CSIR-WRI for making GOG funds available for the project. Also grateful to the Staff of Parasitology Department of the Noguchi Memorial Institute for Medical Research, University of Ghana, and Legon for the Technical assistance given.

\section{References}

AdAm, R. D. (2001) Biology of Giardia lamblia. Clinical Microbiology Reviews 14, 447 - 475.

Adegbola, R. A., Demba E., Deveer, G. \& Todd, F. (1994) Cryptosporidium infection in Gambian children less than 5 years of age. Journal of Tropical Medicine and Hygiene 97, 103 - 107.

Амтоғо J. A. (1997) A survey of microbial pollution of rural domestic water supply in Ghana. Int. J. Envir. Hlth. Res. 7, $121-130$.

Anim-Baidoo, I. (2013) Epidemiology and Molecular Characterization of Giardia lamblia and Cryptosporidium sp. Infections among Children In Accra, Ghana A thesis submitted to the University of Ghana, Legon.

Batchelor, D. J., Tzannes, S., Graham, P. A., Wastling, J. M., Pinchbeck, G. L. \& German, A. J. (2008) Detection of Endoparasites with Zoonotic Potential in Dogs with gastrointestinal Disease in the UK. Transboundary and Emerging Diseases 55, 99 - 104.

BARUtzki, D. \& Schaper, R. (2003) Endoparasites in cattle and cats in Germany 1999 - 2002. Parasitology Research 90, $148-150$.

Biney, C. A. (1987) Changes in the chemistry of a tropical man-made lake, the Densu reservoir, during five years of impoundment. Journal of Tropical Ecology 28, 222 - 231.

Cacciò, S. M., Thompson, R. C. A., Mclauchlin, J. \& Sмiтh, H. V. (2005) Unravelling Cryptosporidium and Giardia epidemiology. Trends in Parasitology 21 (9), 430 - 437.

Cacciò, S. M. \& RYan, U. (2008) Molecular epidemiology of giardiasis. Mol. Biochem.Parasitol. 160, 75 - 80. http://dx.doi.org/10.1016/j.molbiopara.2008.04.006] 
Cook, G. C. (1996) Manson's Tropical Diseases, $20^{\text {th }}$ ed. W. B. Saunders Company Ltd., London.

Craun, G. F., Calderon, R. L. \& Craun, M. F. (2005) Outbreaks associated with recreational water in the United States. International Journal of Environmental Health Research 15 (4), 243 262.

Delport, T. C., Asher, A. J., Beaumont, L. J., WebSter, K. N., Harcourt, R. G. \& Power, M. L. (2014) Giardia duodenalis and Cryptosporidium occurrence in Australian sea lions (NeOphoca cinerea) exposed to varied levels of human interaction. Int. J. Parasitol.: Parasites Wildl. 3, $269-275$.

Enriquez, F. J., Avila, C. R., Santos, J. I., Tanaka-Kido, J., Vallejo, O. \& Sterling, C. R. (1997) Cryptosporidium infections in Mexican children: clinical, nutritional, enteropathogenic and diagnostic evaluations. American Journal of Tropical Medicine and Hygiene 56, 254 257.

Farthing, M. J., Cevallos, G. A. \& P. Kelly In Cook, G. C. (1996) Manson's Tropical Diseases. W.B. Saunders company Limited.

FARTHING, M. J. (1997) The molecular pathogenesis of giardiasis. Journal of Pediatric Gastroenterology and Nutrition 24, $79-88$.

Feng, Y. \& XiaO, L. (2011) Zoonotic potential and molecular epidemiology of Giardiaspecies and giardiasis. Clin. Microbiol. Rev. 24, 110 - 140.

Gordon, C. \& Amatekpor, J. K. (1999) The Sustainable Integrated Development of the Volta Basin in Ghana, Volta Basin Research Project, University of Ghana, Legon Accra, 159p.

Hamnes, I. S., BJørn, K. G. \& Lucy, J. R. (2007) A longitudinal study on the occurrence of Cryptosporidium and Giardia in dogs during their first year of life. Acta Veterinaria Scandinavica; 49 (1), 22.
Heymans, H. S. A., Ronson, D. C. A. \& Van-Hooft, M. A. J. (1987) Loop-mediated-isothermal-amplification-an-advanced-method-for-the-detection-of-giardia.European Journal of Paediatrics 146, $401-403$.

Hoskins, J. D., Malone, J. B. \& Smith, P. H. (1982) Prevalence of parasitism by faecal examination in Louisiana cattle. American Journal of Veterinary Research 43, 1106 - 1109.

Itoh, N., Muroaka, N., Aoki, M. \& Itagaki, T. (2001) Prevalence of Giardia lamblia infection in household cattle (In Japanese, with English translation). Kanshenshogaku Zasshi 75, 671 -677 .

Iqbal, J., Hira, R., Al-Ali, F. \& Philip, R. (2001) Cryptosporidiosis in Kuwaiti children: seasonality and endemicity. Clinical Microbiology and Infection 7, $261-266$.

Jacobs, S. R., Forrester, C. P. R. \& YANG, A. (2001) A survey of the prevalence of Giardia in dogs presented to Canadian veterinary practices. The Canadian Veterinary Journal 42, 45 - 46.

KIRKPATRICK, C. E. (1988) Epizootiology of endoparasitic infections in pet cattle and cats presented to a veterinary teaching hospital. Veterinary Parasitology 30, 1113 - 1124.

Klaus, J.S., Janse, I, Heikoop, J.M. Sanford, R.A. \& Fouke, B.W.(2007) Coral microbial communities, zooxanthellae and mucus along gradients of seawater depth and coastal pollution, Enviromental Microbiology 9, 1291-305, https:// doi.org/10.1111/j.1462-2920.2007.01249.x

Mahato, M. K., Singh, D. K., Rana, H. B. \& Acharya, K. P. (2018) Prevalence and risk factors associated with Giardia duodenalis infection in dairy cattle of Chitwan, Nepal. J Parasit Dis. 42 (1), 122 - 126. doi:10.1007/s12639-017-0975-6

Overgauuw, P. A. (1997) Prevalence of intestinal nematodes of cattle and cats in The Netherlands. Veterinary Quaterly 19, $14-17$. 
Ponce-Macotela, M., Peralta-Abarca, G. E. \& Martínez-Gordillo, M. N. (2005) Giardia intestinalis and other zoonotic parasites: prevalence in adult dogs from the southern part of Mexico City. Veterinary Parasitology 131, 1 -4 .

Rumsey D. J. (2010) Statistical Essentials for Dummies. Hoboken: Wiley Publishing.

Sсотт, C. A., Sмith, H. V., Мтамвo, M. M. A. \& GiBBs, H. A. (1995) An epidemiological study of Cryptosporidium parvum in two herds of adult beef cattle. Veterinary Parasitology 57, $277-288$.

Thompson, R. C. A. (2000) Giardiasis as a re-emerging infectious disease and its zoonotic potential. International Journal of Parasitology 30, $1259-1267$.
Thompson, R. C. A. \& Monis, P. T. (2004) Variation in Giardia: implications for taxonomy and epidemiology. Advances in Parasitology 58, 69 -137 .

Thompson, R.C.A. (2013) Parasite zoonoses and wildlife: One health, spillover and human activity. Int. J. Parasitol. 43, 1079 - 1088.

Vanpariss, O., Hermans, L. \& Van Der Flaes, L. (1991) Helminth and protozoan parasites in cattle and cats in Belgium. Veterinary Parasitology 38, $67-73$.

Vermeulen, E. T., Ashworth, D. L. Eldridge, M. D. B. \& Power, M. L. (2015) Investigation into potential transmission sources of Giardia duodenalis in a threatened marsupial (Petrogale penicillata). Infections, Genetics and Evolution Science Direct 33, 277 - 280.

Received 24 Aug 17; revised 4 Feb 20. 